\title{
Influence of the tidal cycle and a tidal intrusion front on the spatio-temporal distribution of coastal bottlenose dolphins
}

\author{
Sónia Mendes ${ }^{1, *}$, William Turrell ${ }^{2}$, Thomas Lütkebohle ${ }^{3, * *}$, Paul Thompson ${ }^{1}$ \\ ${ }^{1}$ University of Aberdeen, Department of Zoology, Lighthouse Field Station, George Street, Cromarty, Ross-shire IV11 1YJ, \\ Scotland, UK \\ ${ }^{2}$ Fisheries Research Services, Marine Laboratory, PO BOX 101, Victoria Road, Aberdeen AB11 9DB, Scotland, UK \\ ${ }^{3}$ Institut für Meereskunde, University of Kiel, Düsternbrooker Weg 20, 24105 Kiel, Germany
}

\begin{abstract}
Small scale hydrographic fronts may act as convergence zones in which organisms accumulate, and have been used preferentially by several marine predators. In this paper, bottlenose dolphin Tursiops truncatus spatial and temporal distribution was investigated in relation to the tidal cycle and to the spatial and temporal evolution of a tidal front in a narrow estuarine channel. Estimates of dolphin abundance during all states of the tidal cycle, and positions of the frontal surface features and of dolphin groups were obtained from land-based observations. Hydrographic data was obtained on the structure of the front. The results showed that the front was characteristic of tidal intrusion fronts and was predictable both temporally and spatially. Its development could be divided into 3 stages. In the first stage the front was determined by the tidal flows and by an unusual freshwater input at the mouth of the estuary. In later stages the bathymetry and morphology of the estuary dominated and the front became stationary until the tidal inflow stopped, causing the front to dissipate. Dolphins were most abundant during the flood tide, particularly during the stationary stage of the tidal front. Dolphins also showed a spatial association with the area near the surface features of the front, which could be related to increased foraging efficiency resulting from the accumulation of prey in the frontal region. Further work that takes account of the 3D distribution and behaviour of the dolphins and their prey with relation to the front is now required to fully understand the nature of this relationship.
\end{abstract}

KEY WORDS: Tides - Tidal intrusion front - Dolphin distribution - Tursiops truncatus · Foraging efficiency $\cdot$ Scotland

Resale or republication not permitted without written consent of the publisher

\section{INTRODUCTION}

Tidal fronts are hydrographic features that occur at small spatial scales, and their characteristics are largely determined by the diurnal and fortnightly periodicity of tidal movement, the magnitude of fresh water supply, and the configuration of the estuary (Bowman \& Iverson 1978). Hydrographic fronts may be

*E-mail: sonia.mendes@sepa.org.uk

${ }^{* *}$ Present address: Lange Reihe 5, 22941 Jersbek, Germany defined as regions where steep horizontal gradients in temperature, salinity, density or velocity occur (Huzzey 1982). These features may act as convergence zones in which organisms accumulate (Franks 1992), and have been used preferentially by several marine predators. For example, foraging seabirds have been associated with tidal fronts (Hunt \& Schneider 1987, Decker \& Hunt 1996, Hunt et al. 1998), as well as basking sharks Cetorinus maximus (Sims \& Quayle 1998), while several species of tuna (e.g. Thunnus alalunga) have been found foraging at oceanic fronts (Fiedler \& Bernard 1987). 
Cetacean spatial and temporal distributions have also been related to oceanographic fronts (Kenney \& Winn 1986, Viale \& Frontier 1994). Sighting rates of sperm whales Physeter macrocephalus, increased in the vicinity of a thermal front off Georges Bank, USA, possibly because the front provided suitable habitat for their squid prey (Griffin 1999). In the Gulf of Mexico, Baumgartner (1997) showed that Risso's dolphin Grampus griseus were sighted more frequently along the steep sections of the upper continental slope, and discussed that this was probably due to an accumulation of prey caused by the generation of fronts in the area. Dustan \& Pinckney (1989) also provided anecdotal descriptions of bottlenose dolphins Tursiops truncatus being sighted frequently in the vicinity of an estuarine front in Charleston Harbour, USA.

In the inner Moray Firth, NE Scotland, bottlenose dolphins are frequently seen in the Kessock Channel (Fig. 1), particularly during the summer months (Wilson et al. 1997). Anecdotal observations have suggested that dolphins are predominantly sighted during the flood tide. A repeated feature of the flood tide is a distinctive front, which forms in the channel where the tidal flow encounters the brackish water of the Beauly Firth (Fig. 1). A V-shaped line of increased turbulence, foam and occasional floating debris usually mark the position of the surface expression of this tidal front (Fig. 2), and this remains visible for part of the flood tide. The front is repeatedly seen propagating into the channel, reaching a stationary position, and then dissipating towards high water (HW). Anedoctal observations have suggested that dolphins at Kessock are associated with the frontal region, but this hypothesis has not previously been tested.

This study investigated the spatio-temporal distribution of bottlenose dolphins in this narrow estuarine channel in relation to the tidal cycle and to the front that occurs over the flood tide. The following hypotheses were examined: (1) the number of dolphins present at Kessock is higher during the flood tide; (2) a tidal intrusion front forms during the flood tide in the Kessock Channel; (3) dolphins distribute themselves preferentially in the frontal region.

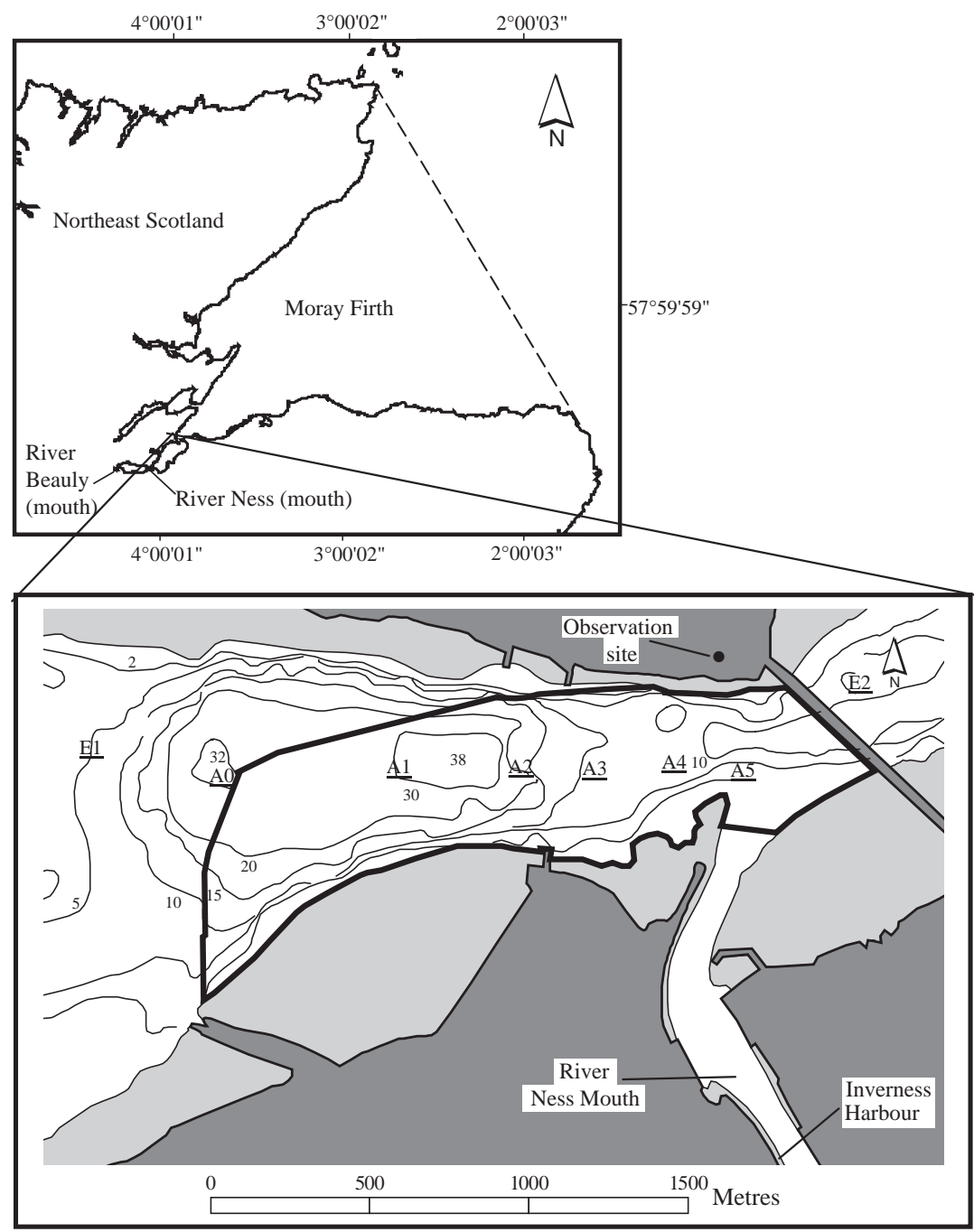

Fig. 1. Location and bathymetry of the study area. The thicker black line outlines the core area observed in 2000. The CTD stations are represented as letters and numbers. The shaded area represents the intertidal zone while the darker area represents the land

\section{STUDY AREA}

The study was conducted in the Kessock Channel, Moray Firth, Northeast Scotland (57 $50^{\prime} \mathrm{N}, 04^{\circ} 23^{\prime} \mathrm{W}$, Fig. 1). The Kessock Channel is the narrow area where the Beauly and the Inverness Firths merge into a hydrographic system $24 \mathrm{~km}$ in length (Hunter \& Rendall 1986). The channel is approximately $2 \mathrm{~km}$ long and $0.5 \mathrm{~km}$ wide, covering an area of approximately $0.90 \mathrm{~km}^{2}$. It has rapid changes in bottom relief, a sill and a deeper basin with a maximum water depth of $38 \mathrm{~m}$. Tides in the inner Moray Firth are semi-diurnal and the Inverness and Beauly Firths have typical tidal ranges of $1.9 \mathrm{~m}$ at neap tides and $4.1 \mathrm{~m}$ at spring tides (Mendes 2000). This channel exhibits strong tidal currents with peak flows aligned along its central axis and 


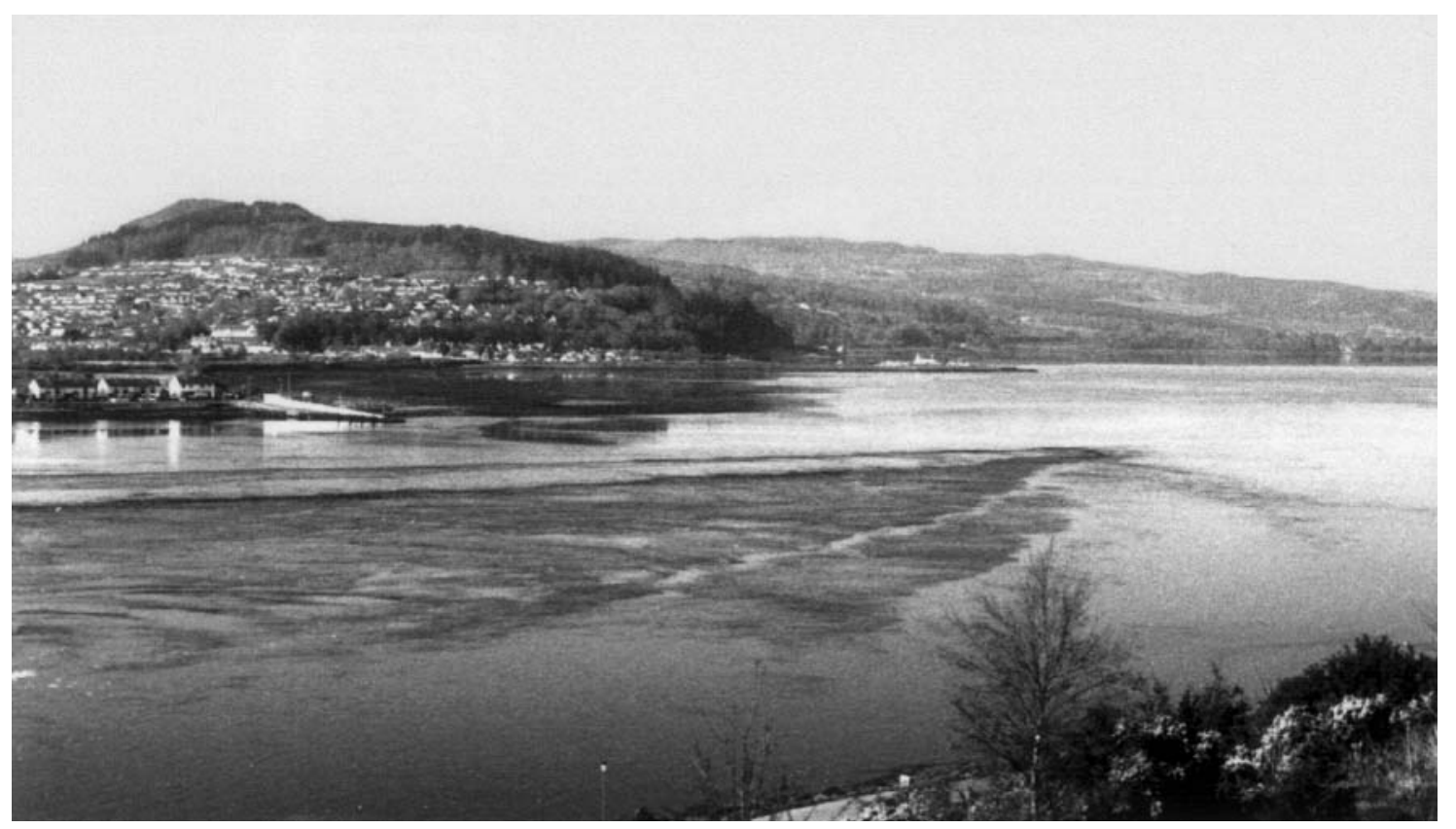

Fig. 2. V-shaped tidal front in the Kessock Channel around $3 \mathrm{~h}$ before HW as seen from the observation site looking southwest

flow rates exceeding $0.75 \mathrm{~m} \mathrm{~s}^{-1}$. There are 2 freshwater sources in the Beauly Firth, 1 at the head (the river Beauly) and 1 at the mouth (the river Ness, Fig. 1), in the Kessock Channel.

\section{MATERIALS AND METHODS}

Influence of tidal cycle on abundance of dolphins in the Kessock Channel. The relationship between the tidal cycle and changes in the abundance of dolphins in the Kessock Channel was investigated between July and September 1994. Observations were made by one person on $51 \mathrm{~d}$ from a site on the north shore of the channel $\left(57^{\circ} 30^{\prime} \mathrm{N}, 04^{\circ} 14^{\prime} \mathrm{W}\right), 31 \mathrm{~m}$ above chart datum. Data were collected over $6 \mathrm{~h}$ sampling periods, alternating between morning (08:30 to $14: 30 \mathrm{~h}$ ) and afternoon (13:30 to $19: 30 \mathrm{~h}$ ) periods to provide an even spread throughout the day and over all stages of the tidal cycle.

During each $6 \mathrm{~h}$ observation period, the study area was scanned for $10 \mathrm{~min} \mathrm{~h}^{-1}$, and observations of surfacing dolphins within that period were used to produce a single estimate of the number of dolphins present in that hour. The effect of the tidal cycle on the number of dolphins present was assessed using a Kruskal-Wallis test because the data were not normally distributed.

Characterisation of the tidal front. Between May and August 2000, regular land-based observations were made by one person to characterise spatial and temporal variations in the surface features of the tidal front. Data were collected for $27 \mathrm{~d}$, from the same landbased site used in 1994, using a surveyor's theodolite (Leica T460). Observations were made throughout the flood tide, from approximately $1.5 \mathrm{~h}$ after low water until high water, when the weather conditions allowed. Each day, the time at which the tidal front was first detected in the study area was recorded and thereafter positions of the pronounced foam and turbulence lines were recorded every $20 \mathrm{~min}$. The number of positions recorded was related to the number of points thought to be sufficient to reproduce the front during the analyses. The time that the front's pronounced V-shaped pattern dissipated was also recorded.

The theodolite was calibrated by manoeuvring an inflatable boat within the study area, and acquiring 30 geographic positions with a Differential Global Positioning System (DGPS) unit (Garmin GPS 12 XL Personal Navigator and MBX3 Differential Beacon Receiver), at the same time as recording corresponding positions with the theodolite. The median theodolite error calculated by the calibration was $16.70 \mathrm{~m}$ (Inter Quartile Range [IQR] 9.95-18.36), well within the limits reported for a $30 \mathrm{~m}$ high theodolite station (Würsig et al. 1991).

The 3D hydrographic structure of the front was studied on the 9 June 2000 using a CTD (conductivity temperature density; Model STD-12, Applied Microsystems) deployed from an inflatable boat. A DGPS unit was used to position the boat at the chosen stations.

A total of 24 CTD casts were made in a pre-set survey pattern consisting of 2 endpoints (western and 
eastern), and an axial longitudinal section spanning a distance of approximately $2700 \mathrm{~m}$ from one endpoint to the other (Fig. 1). Time, geographic position, water depth and observations of the surface visual features were also recorded. To study the spatio-temporal hydrographic characteristics of the tidal front, vertical contour plots of temperature, salinity and density (sigma-t) were examined.

Associations between dolphins and surface features of the tidal front. In 2000, during the land-based studies of the front's characteristics, data were also collected on the position of groups of dolphins sighted. The study area was scanned for the presence of dolphins for a $5 \mathrm{~min}$ period every $20 \mathrm{~min}$. From this observation site it was assumed that there was an equal probability of sighting dolphins throughout the study area, as the study area was small and dolphins were easily detected. During each 5 min scan, the position of each group was recorded using the theodolite. Groups were defined as an 'aggregation of animals whose members were within $100 \mathrm{~m}$ of one another, engaged in similar activities and, if moving, heading in the same direction (Wells et al. 1987)' or lone individuals separated by more than $100 \mathrm{~m}$. The position of the group was recorded as the position of the first dolphin within the group to be seen at the surface. This, together with alternating measurements of frontal features provided 3 independent samples $\mathrm{h}^{-1}$, of both dolphin groups and the front's position.

Recorded angles to the positions of both the front and dolphins were transformed into geographic coordinates and plotted onto a chart of the study area using ArcView GIS 3.2 (ESRI). Tidal height data, necessary to convert theodolite readings to geographical co-ordinates were obtained from the Inverness Port Authority from a tide gauge located in Inverness harbour (see Fig. 1).

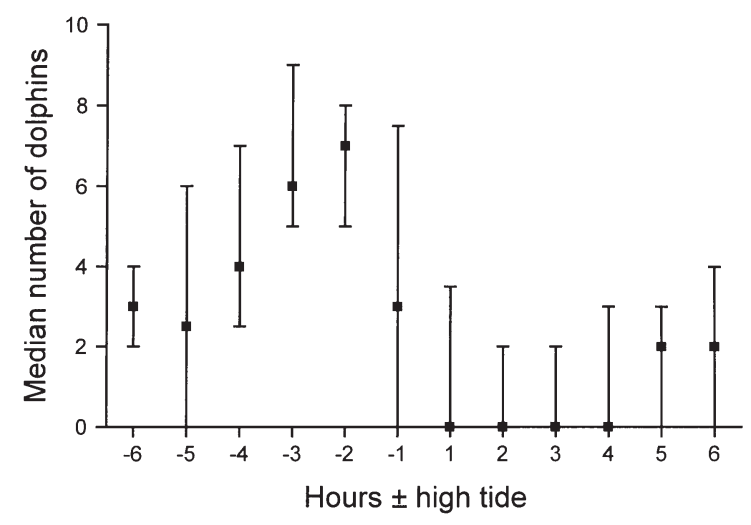

Fig. 3. Tursiops truncatus. Median number of dolphins present in the Kessock Channel with relation to time of HW. The error bars represent the interquartile ranges
To compare the position of the dolphins with the position of the front, we first produced an averaged position for the stationary stage of the front. Dolphin groups were then assigned to different distance classes $(0-50 \mathrm{~m}, 50-100 \mathrm{~m}, 100-150 \mathrm{~m}, 150-200 \mathrm{~m}$, 200-250 m, 250-1220 m), between the minimum and the maximum possible radial distance from the averaged front position. Observed and expected distributions were compared using a Chi-square test. The expected value of dolphin groups in each distance class was obtained by multiplying the total number of observed groups by the area occupied by each distance class, and then dividing by the total study area.

\section{RESULTS}

Tidal cycle influence on dolphin abundance

Through the summer of 1994, observations were made over $217 \mathrm{~h}$. The results show a highly significant difference (Kruskal-Wallis $=67.0, \mathrm{df}=11, \mathrm{p}<0.001$ ) in the median number of dolphins estimated in relation to different states of the tidal cycle, with more dolphins being sighted during the flood tide (Fig. 3).

\section{Characterisation of the tidal front}

A time-series of maps showing the evolution of the visual portion of the front during a 'typical' flood tide is shown in Fig. 4. At the start of the tidal intrusion into the Kessock Channel (around 4 h 30 min before HW) a line of increased turbulence began to form seaward of the river Ness (Fig. 4a). As the tidal speed increased it pushed the front further into the channel past the mouth of the river Ness (Fig. 4b). Approximately $1 \mathrm{~h}$ after the front first appeared, its propagation was arrested, and the front remained fairly stationary for around 2 h 30 min. During its hour-long propagation the front's apex travelled approximately $850 \mathrm{~m}$ along the central axis of the channel, into the Beauly Firth, assuming its characteristic V-shape (Fig. 4c,d). The stationary position corresponded to the area where the channel deepens and widens and the front did not pass upstream of this area. Once the tidal current weakened (around $1 \mathrm{~h}$ before HW), the front began to decay and the V-shape dissipated, although the southern arm of the $\mathrm{V}$ was still visible (Fig. 4e). Approaching HW all frontal features disappeared and a period of slack water was evident (Fig. 4f).

Fig. 5 summarises the data at the time the front started to form and dissipated, in relation to HW during the period studied. The average time the front started to form was $4 \mathrm{~h} 41 \mathrm{~min} \pm 29 \mathrm{~min}$ before HW, while the 
average time the $\mathrm{V}$-shape pattern dissipated was $1 \mathrm{~h}$ $18 \mathrm{~min} \pm 18 \mathrm{~min}$ before HW. The location where the front first appeared was remarkably consistent between days, as was the location in which it became stationary. From one location to the other, the front was displaced on average $857.7 \pm 20.8 \mathrm{~m}$, measured from the change in location of the apex (most western point of the intersection between the 2 arms of the V).

Quasi-synoptic sections of the vertical structure of the water column, along the axis of the channel, are presented in Figs. $6 \mathrm{a}, \mathrm{b}, \mathrm{c}, \& \mathrm{7a}, \mathrm{b}$. The data described here were collected between $-3 \mathrm{~h} 20 \mathrm{~min}$ to $+40 \mathrm{~min}$ relative to HW. The contour plots show that the density structure within the channel was dominated by salinity, which is characteristic of estuaries (Dyer 1997, Fig. 6).



Fig. 5. Time of front formation and dissipation with relation to time of HW

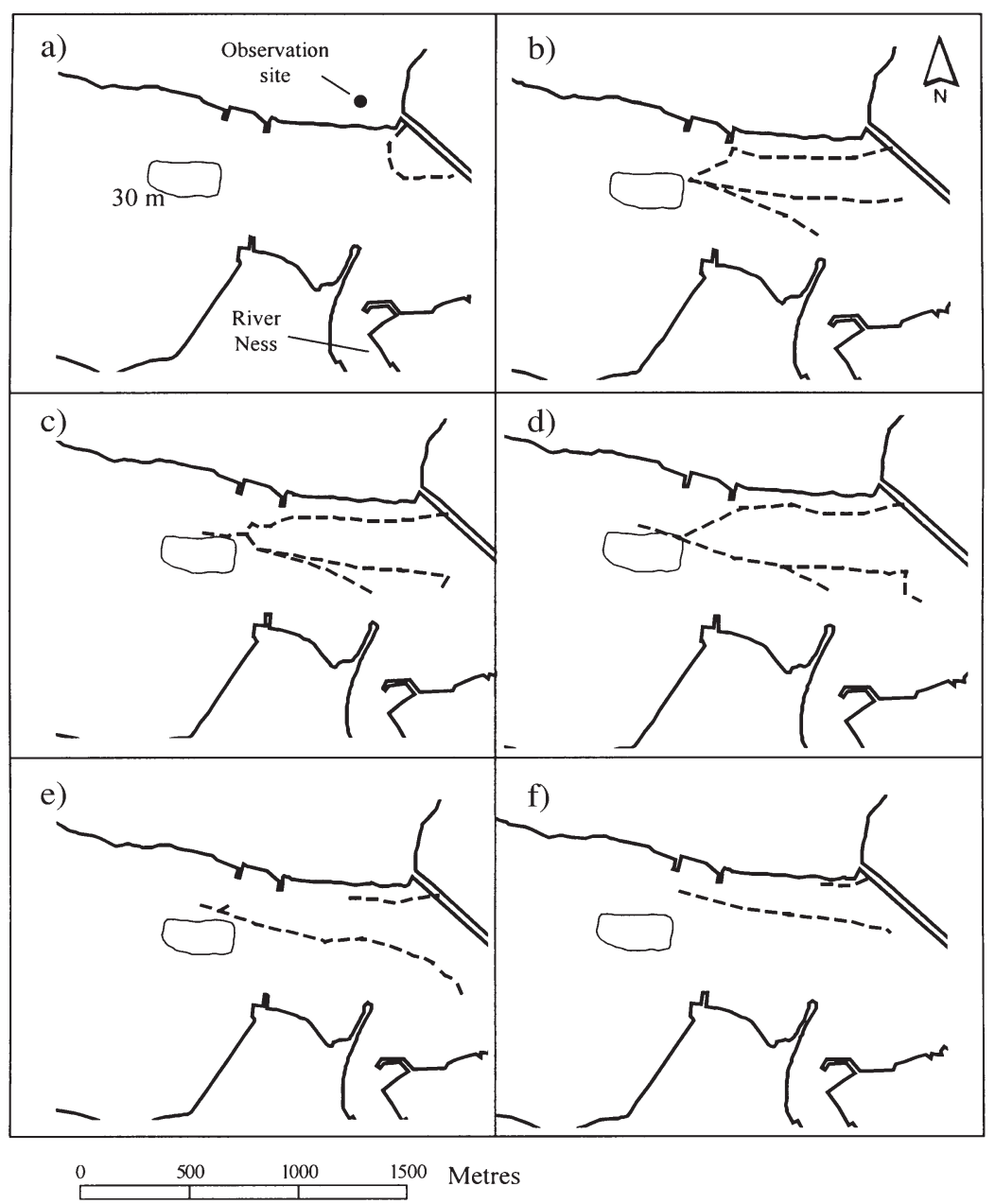

Fig. 4. Time-series showing the development of the surface expression of the tidal front. (a) 4 h 30 min before HW; (b) 3 h 50 min before HW; (c) 3 h $10 \mathrm{~min}$ before HW; (d) 2 h 30 min before HW; (e) 1 h 50 min before HW; (f) 1 h 10 min before HW. The dashed line represents the front. In (a) the line marked with $30 \mathrm{~m}$ is the $30 \mathrm{~m}$ depth contour. Propagation stage is shown in (a) and (b); stationary stage in (c) and (d); and dissipation stage in (e) and (f)
During the early part of tidal intrusion at Kessock, a surface lens of less saline water, derived from the river Ness run-off, was pushed back into the estuary by tidal currents. Fig. 6a shows that the structure of this less saline lens was highly stratified and was located upstream of a steep horizontal gradient, which occupied approximately the first $15 \mathrm{~m}$ of the water column. This front was the transition zone between the less saline lens and the well-mixed, more saline water, and spread itself for approximately $250 \mathrm{~m}$ (Fig. 6). At this stage, the lens was already cut-off from its freshwater supply (river Ness) and the surface expression of the tidal front was very obvious between Stns A2 and A3 by an increase in visible surface turbulence. Landward of the front, distinctive upwelling boils were apparent at the surface. Fig. 7 a shows the intrusion of denser waters at depth, below the stratified less saline lens which has started to erode. Approaching HW, the intrusion of saline water (represented by iso-pycnal 22) filled the basin (Fig. 7b). The almost complete erosion of the surface lens was apparent. We can also see that at HW the river Ness's influence is very obvious, detected by the presence of a less saline surface layer, less than $2 \mathrm{~m}$ deep, spreading outside the river mouth. 



Fig. 6. (a) Salinity, (b) temperature and (c) sigma- $t$ vertical distributions in the axial section of the Kessock Channel around $3 \mathrm{~h}$ before high water, on 9 June 2000. The dotted lines represent the CTD stations from left (west) to right (east)

\section{Dolphins' spatial association with the surface expression of the tidal front}

A total of 109 dolphin group positions (51 samples) were obtained during 7 of the observation days in 2000. These encompass 41 samples when the front was stationary and 10 samples when the front was dissipating, which correspond to 85 and 24 dolphin group positions, respectively (Fig. 8). No dolphins were sighted when the front was propagating. Only those positions obtained when the front was stationary were used for the analyses. An averaged front position was obtained by plotting the mid-line of a polygon, which encompassed the recorded positions representing the tidal front, from all the samples taken when the front was considered stationary (from approximately $3 \mathrm{~h} 30 \mathrm{~min}$ to $1 \mathrm{~h}$ before HW). This averaged front position was assumed to be a reasonable proxy of the real front position at any time during the stationary stage of the front in the channel, as there was considerable overlap in the positions (Fig. 8). The median radial distance of dolphins to the averaged front position was $73 \mathrm{~m}$ (IQR 40 to 128) (Figs. 8 \& 9). The observed distribution of the radial distances between the position of dolphins and the position of the averaged front was significantly different from the expected distribution $\left(\chi^{2}=74.79, \mathrm{p}<0.001, \mathrm{df}=4\right)$ (Fig. 9).

\section{DISCUSSION}

\section{Formation and evolution of the tidal front}

Our observations show that the tidal front in the Kessock Channel is persistent during the greater part of the flood tide, is stationary for most of its duration, and is predictable, both in time and space. The small variations observed during the study period in the temporal and spatial predictability of the front (time of formation and dissipation, front's displacement and stationary location, Figs. $5 \& 8$ ) could be accounted for by the neap/spring cycle, changes in river flow and climatic conditions. These variations are thought to be negligible in the overall predictability of the front's pattern (Mendes 2000) and in its ecological significance. The evolution and vertical structure of the tidal front, shown by the hydrographic data, correlate well with the observed surface features. The data collected confirm that this front is a 'tidal intrusion front' as described by Simpson \& Nunes (1981). Tidal intrusion fronts are ephemeral density fronts commonly associated with narrow, internally stratified estuaries subjected to strong tidal flows, and have been described for several other estuaries such as Seiont in Wales, Port Hacking in Australia and Chesapeake Bay in the USA (Simpson \& Nunes 1981, Huzzey 1982, Marmorino \& Trump 1996, Marmorino et al. 1999). 

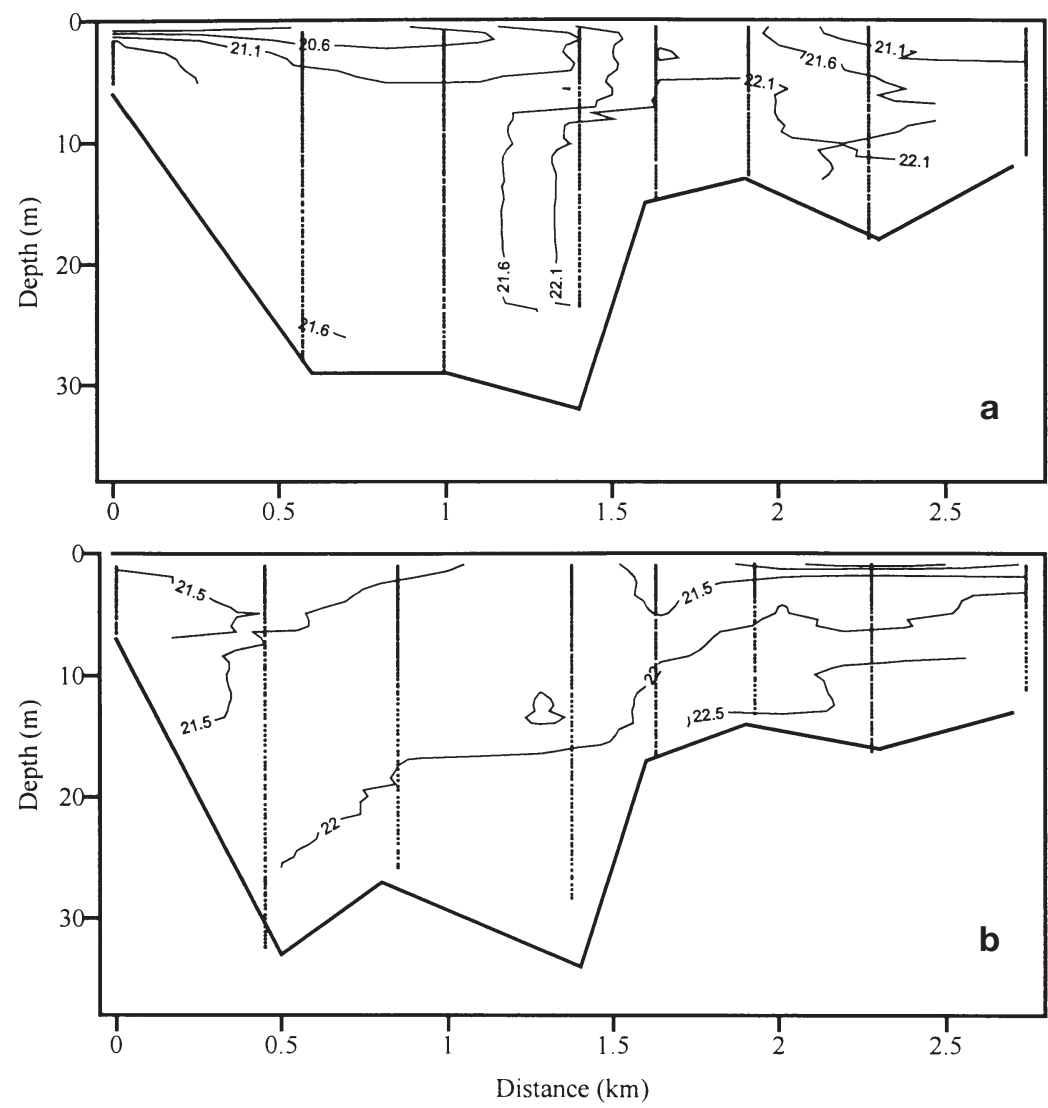

Fig. 7. Sigma-t vertical distributions in the axial section of the Kessock Channel around (a) $2 \mathrm{~h}$ and (b) 30 min before HW, on 9 June 2000. The dotted lines represent the CTD stations from left (west) to right (east)

The formation and evolution of the tidal intrusion front described here occurs over approximately $4 \mathrm{~h}$ each flood tide, the same duration as the one described by Huzzey (1982), and can be broadly split into 3 stages:

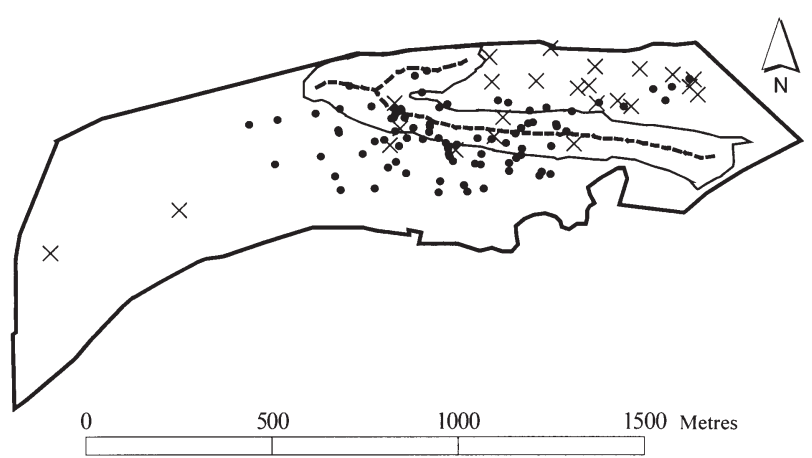

Fig. 8. Tursiops truncatus. Distribution of dolphin groups in relation to an averaged front position. The dashed line is the averaged front and the polygon around it represents the limits of all the recorded front positions when the front is considered stationary. •: dolphin groups recorded when the front was stationary; and $x$ : when the front was dissipating
(1) Formation and propagation stage. At slack low water the river Ness fills the sill region with a surface lens of low salinity water. Approximately $4 \mathrm{~h} 30 \mathrm{~min}$ before HW the front starts to form at the seaward edge of the lens. Tidal and less saline waters converge in the frontal region, the less saline flow is swept back while the tidal flow plunges beneath the less saline lens (Simpson \& Nunes 1981). As the tidal speeds strengthen the less saline lens is transported upstream past the mouth of the river Ness, and hence further supply of freshwater to the lens is cut off.

(2) Stationary stage. Once the front reaches the western end of the sill region, approximately $3 \mathrm{~h} 30 \mathrm{~min}$ before HW, the bathymetry and morphology of the channel become dominant as it rapidly widens and deepens. The front becomes arrested and remains stationary in this location until tidal currents weaken. During this stage it is likely that the 2 water layers of distinct densities mix in the process of plunging (Largier 1992). A combination of the turbulence generated at the halocline and the turbulence generated by external stress (e.g. shear at the seabed) results in the cross-interface mixing of salt and fresher water (Dyer 1997). This process destabilises the system, resulting in decreased stratification (Simpson et al. 1990), which is apparent in the data presented here (e.g. Fig. 7a). The same sequence of events has been noticed in the Conwy and Dulas estuaries in Wales (Pelegri 1988). The upward transport of denser water entraining into the less saline layer could explain the upwelling boils seen west of the front.

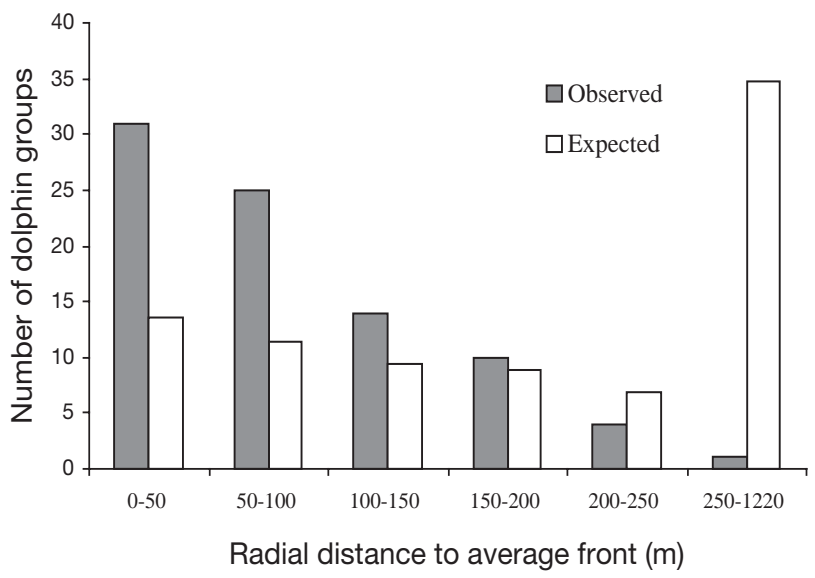

Fig. 9. Tursiops truncatus. Observed distribution of dolphin groups in relation to radial distance to the averaged front compared with the expected distribution 
(3) Dissipation stage. Approaching HW, tidal flow intensity diminishes, and the shallow less saline lens derived from the river Ness starts to re-form at the sill. As the flood starts, it is displaced west re-starting the cycle. At this stage the density gradient that characterised the front has dissipated and the water column at the basin is a well-mixed structure.

\section{Tidal influence on dolphin spatio-temporal distribution}

Bottlenose dolphins were significantly more abundant in the study area during the flood tide (Fig. 3), especially during the period when the front was stationary ( $3 \mathrm{~h} 30 \mathrm{~min}$ to $1 \mathrm{~h}$ before HW). Although data on dolphin abundance were collected some years before the study of the front's characteristics, there is no reason to believe that the predictable behaviour of the front would have differed in this earlier period. Anecdotal evidence gathered over the last $10 \mathrm{yr}$, during regular dolphin surveys in the Kessock channel (Thompson et al. 2000), indicates that during this period the observed timing and location of the front have not changed.

Although the data in Fig. 3 remain the most extensive of this kind for this study area, subsequent studies have also noted that the dolphins' presence and abundance in the Kessock Channel is strongly linked to the tidal cycle (Thompson et al. 2000), while authors elsewhere have also suggested that dolphin movements may be related to tidal currents. In Florida, Scott et al. (1990) found that bottlenose dolphins and striped mullet Mugil cephalus visited shallow seagrass meadows on the rising tide, and Acevedo \& Würsig (1991) also suggested that tidal movements of bottlenose dolphins were related to the movement patterns of their potential prey.

The results also suggest that dolphins are spatially associated with the area near the surface features of the tidal intrusion front. The reasons for this association remain unclear, but seem likely to be due to the front influencing dolphin prey distribution or behaviour. It has been suggested that the seasonality of dolphin sightings in this area could be related to the seasonal migrations of adult salmonids (atlantic salmon Salmo salar and sea trout Salmo trutta) up the rivers Ness and Beauly to spawn (Wilson et al. 1997). Direct observations (Janik 2000) and diet studies (Santos et al. 1995, Santos et al. 2001) have shown that salmonids occur in the diet of bottlenose dolphins from this area. We suggest that dolphins may be using the frontal region as a feeding habitat, due to a potential accumulation of salmonids near the front. Physical mechanisms change dramatically in the vicinity of a front and may lead to an increase in biomass caused by a directed swimming behaviour or due to the accumula- tion of less mobile organisms at the convergence zone, making them more vulnerable to predators (Franks 1992). Adult atlantic salmon do not feed as they migrate upstream so it does not seem likely that these fish would be actively seeking the frontal region in response to an increase in prey. However, salmon could be gathering in the front to obtain important cues to the homing process. Salmon might obtain olfactory cues through haloclines between adjacent horizontally flowing water masses (Quinn \& terHart 1987, Olson \& Quinn 1993) such as the ones encountered in the front studied here. Salmon can also become disorientated when encountering complex current flows, and may aggregate temporarily until they reorientate themselves (Quinn \& terHart 1987). Other studies carried out on atlantic salmon and other salmonid species (e.g. chinook salmon Oncorhynchus tshawytscha) have found that these fish can also be passively transported by tidal movements (Olson \& Quinn 1993, Aprahamian et al. 1998), and appear to have a general preference for near-surface waters (Quinn \& terHart 1987, Olson \& Quinn 1993), which could favour their advection towards the convergence zone. Below the surface, the frontal region will normally be wider, with the halocline extending and sloping downwards from the horizontal plane (Franks 1992). Thus, work that takes account of 3D distribution and behaviour of dolphins and their prey, with relation to the front, is now required to fully understand the nature of this relationship.

This study has highlighted spatial and temporal associations between bottlenose dolphins and a tidal intrusion front, but the mechanisms that attract these animals to the frontal region remain uncertain. Highly mobile marine predators are found to rapidly associate with ephemeral features such as hydrographic fronts where these are predictable both in time and space (Decker \& Hunt 1996). The temporal and spatial predictability of the front in this channel may be of particular importance in focusing foraging efforts, improving efficiency and therefore reducing metabolic costs involved in the search for food (Williams et al. 1996). Wilson et al. 1997 suggested that, in the Moray Firth, dolphin prey could concentrate in narrows such as the Kessock Channel. It may be a combination of the tidal intrusion front with the channel's bathymetry and configuration that attracts fish and dolphins to this area.

Acknowledgements. A special thanks to the people that helped with data collection, in 1994, Antje Helms, Jutta Uhrigshart, Rolf Lakämper, Ingo Lütkebohle, Joan and Will Davidson, and Hugh, and in 2000, Tim Barton, René Swift, Helen Pitts, Leigh Hickmott and Gordon Hastie. Many thanks to Jeff, Ernie and Keith, at the Kessock Bridge (Highland Council Roads Department); to Capt. McLoed and Ken MacLean at the Inverness Ports Authority for providing the 
daily measures of sea level at Inverness; to John and Martin (Kessock Boat Centre) and to the Kessock RNLI for allowing the use of their facilities; and to Sarah Hughes (FRS Marine Lab). Thanks to Tim Barton, René Swift, Kate Grellier, Stuart Middlemas and Vincent Janik who provided useful comments on previous drafts of this manuscript as well as to 4 anonymous reviewers for their helpful suggestions on the manuscript. Fieldwork in 1994 was funded by Scottish Natural Heritage. S.M. was supported through an MSc studentship by PRAXIS XXI-Ministry of Science and TechnologyPortugal.

\section{LITERATURE CITED}

Acevedo A, Würsig B (1991) Preliminary observations on bottlenose dolphins, Tursiops truncatus, at Isla del Coco, Costa Rica. Aquat Mamm 17(3):148-151

Aprahamian MW, Jones GO, Gough PJ (1998) Movement of adult Atlantic salmon in the Usk estuary, Wales. J Fish Biol 53(1):221-225

Baumgartner MF (1997) The distribution of Risso's dolphin (Grampus griseus) with respect to the physiography of the northern Gulf of Mexico. Mar Mamm Sci 13(4):614-638

Bowman MJ, Iverson RI (1978) Estuarine and plume fronts. In: Bowman MJ, Esaias WE (eds) Oceanic fronts in coastal processes. Springer-Verlag, New York, p 87-104

Decker MB, Hunt GL (1996) Foraging by murres (Uria spp.) at tidal fronts surrounding the Pribilof Islands, Alaska, USA. Mar Ecol Prog Ser 139:1-10

Dustan P, Pinckney JL Jr (1989) Tidally induced estuarine phytoplankton patchiness. Limnol Oceanogr 34:410-419

Dyer KR (1997) Estuaries-a physical introduction. John Wiley \& Sons, Oxford

Fiedler PC, Bernard HJ (1987) Tuna aggregation and feeding near fronts observed in satellite imagery. Cont Shelf Res 7: 871-881

Franks PJS (1992) Sink or swim: accumulation of biomass at fronts. Mar Ecol Prog Ser 82:1-12

Griffin RB (1999) Sperm whale distributions and community ecology associated with warm-core ring off Georges Bank. Mar Mamm Sci 15(1):33-51

Hunt GL, Schneider DC (1987) Scale-dependent processes in the physical and biological environment of marine birds. In: Croxall JP (ed) Seabirds feeding ecology and role in the marine ecosystems. Cambridge University Press, Cambridge, p 7-42

Hunt GL, Russell RW, Coyle KO, Weingartner T (1998) Comparative foraging ecology of planktivorous auklets in relation to ocean physics and prey availability. Mar Ecol Prog Ser 167:241-259

Hunter J, Rendall D (1986) Water quality in the Inverness and Beauly Firths. Proc R Soc Ed 91B:315-327

Huzzey LM (1982) The dynamics of a bathymetrically arrested estuarine front. Estuar Coast Shelf Sci 15:537-552

Janik VM (2000) Food-related bray calls in wild bottlenose dolphins (Tursiops truncatus). Proc R Soc Lond B 267: 923-927

Kenney RD, Winn HE (1986) Cetacean high-use habitats of the Northeast United States continental shelf. Fish Bull 84(2):345-357

Largier JL (1992) Tidal intrusion fronts. Estuaries 15(1):26-39

Marmorino GO, Trump CL (1996) High-resolution measure-

Editorial responsibility: Otto Kinne (Editor),

Oldendorf/Luhe, Germany ments made across a tidal intrusion front. J Geophys Res 101(25):661-674

Marmorino GO, Trump CL, Trizina DB (1999) Preliminary observation of a tidal intrusion front inside the mouth of the Chesapeake Bay. Estuaries 22(1):105-112

Mendes S (2000) The relative importance of a tidal intrusion front and bathymetry to the distribution of bottlenose dolphins in a narrow channel. MSc thesis, University of Aberdeen

Olson AF, Quinn TP (1993) Vertical and horizontal movements of adult chinook salmon, Oncorhynchus tshawytscha, in the Columbia River estuary. Fish Bull 91:171-178

Pelegri JL (1988) Tidal fronts in estuaries. Estuar Coast Shelf Sci 27:45-60

Quinn TP, terHart BA (1987) Movements of adult sockeye salmon (Oncorhynchus nerka) in British Columbia coastal waters in relation to temperature and salinity stratification: ultrasonic telemetry results. Can Fish Aquat Sci Spec Publ 96:61-77

Santos MB, Pierce GJ, Wijnsma G, Ross HM, Reid RJ (1995) Diets of small cetaceans stranded in Scotland 1993-1995. ICES Counc Meet Pap 6

Santos MB, Pierce GJ, Reid RJ, Patterson IAP, Ross HM, Mente E (2001) Stomach contents of bottlenose dolphins (Tursiops truncatus) in Scottish waters. J Mar Biol Assoc UK 81:873-878

Scott MD, Irvine AB, Wells RS (1990) A long-term study of bottlenose dolphins on the west coast of Florida. In: Leatherwood S, Reeves RR (eds) The bottlenose dolphin. Academic Press, San Diego, p 235-244

Simpson JH, Nunes RA (1981) The tidal intrusion front: an estuarine convergence zone. Estuar Coast Shelf Sci 13: $257-266$

Simpson JH, Brown J, Matthews J, Allen G (1990) Tidal straining, density currents, and stirring in the control of estuarine stratification. Estuaries 13(2):125-132

Sims DW, Quayle VA (1998) Selective foraging behaviour of basking sharks on zooplankton in a small-scale front. Nature 393:460-464

Thompson P, Tufft L, Spencer N, Grellier K, Durban J (2000) Evaluation of techniques for monitoring the abundance and behaviour of bottlenose dolphins-the Kessock Channel as a case study. Scottish Natural Heritage Commissioned Report F99LE01 (unpubl. report)

Viale D, Frontier S (1994) Surface megafauna related to western Mediterranean circulation. Aquat Living Resour 7:105-126

Wells RS, Scott MD, Irvine AB (1987) The social structure of free-ranging bottlenose dolphins. In: Genoways HH (ed) Current mammalogy, Vol 1. Plenum Press, New York, p 247-305

Williams T, Shippee S, Rothe M (1996) Strategies for reducing foraging costs in dolphins. In: Greenstreet S, Tasker M (eds) Aquatic predators and their prey. Fishing News Books, University Press, Cambridge, p 4-9

Wilson B, Thompson PM, Hammond PS (1997) Habitat use by bottlenose dolphins: seasonal distribution and stratified movement patterns in the Moray Firth, Scotland. J Appl Ecol 34:1365-1374

Würsig B, Cipriano F, Würsig M (1991) Dolphin movement patterns (information from radio and theodolite tracking studies). In: Pryor K, Norris K (eds) Dolphin societiesdiscoveries and puzzles. University of California Press, Berkeley, p 78-90

Submitted: June 25, 2001; Accepted: April 23, 2002

Proofs received from author(s): July 26, 2002 